163 CIINTCAL RETEVANCE OF THE INSULINN-LIKE GROWIH FACTORS 463 Phillip DK Lee, Darrell M Wilson, Raymond L Hintz, Ron G Rosenfeld. Pediatrics, Stanford Univ, , Staniford. We have reviewed our experience with radioimanoassays of insulin-like growth factors, IGF-I and II, to determine their
utility in the evaluation of short stature. IGF-I and II were utility in the evaluation of short stature. I GF-I and (NS) (height > 2 s.d. below mean, GH peak $<7 \mathrm{ng} / \mathrm{ml}$ ) and growth hormone deficient (GHD) children by radioimmunoassay using the NIADDK anti-serum for IGF-I and a specific antibody to the C-peptide region of IGF-II. An age-related boundary for IGF-I and a level of $300 \mathrm{ng} / \mathrm{ml}$ for IGF-II were used to classify values as nomal or low. Results are given in the table as [low values]/[total per group].

$$
\begin{aligned}
& \begin{array}{lccc} 
& \text { IGF-I }(\mathrm{N}=265) & \text { IGF-II } & (\mathrm{N}=263) \\
\mathrm{NL} & 10 / 194(58) & 9 / 195 & (98) \\
\mathrm{GHD} & 60 / 65(92 \%) & 33 / 59 & (56 \%)
\end{array} \\
& \begin{array}{lllll}
\text { GHD } & 9 / 10 & (908) & 5 / 9 & (558)
\end{array}
\end{aligned}
$$

IGF-I is a far better indicator of GHD than IGF-II. Using a criterion of either low IGF-I or II, 62/65 (95\%) of GHD cases and $18 / 195$ ( 98 ) of NL would have been identified. 5/7 false positives for IGF-I occurred below age 5 and $4 / 5$ false negatives occurred above age 8. Interestingly, the proportion of low values for both IGF-I and II in the NS group are similar to those observed for the GHD group. We conclude that IGF-I and to a lesser extent IGF-II levels are useful in identifying a child with possible GHD. Our data also demonstrate significant overlap in IGF-I and II levels in GHD and NS children, suggesting that a subset of NS has abnormalities in physiologic GH secretion which are not revealed by provocative testing. CHLLDHOOD LEAD TOXICITY IS NOT ASSOCIATED WITH AB-
NORMALITIES IN SERUM THYROXINE (T4) CONCENTRATIONS. Morri E. Markowitz and John F. Rosen. Dept. of Pediatrics, Albert Einstein College of Medicine, Montefiore Medical Center, Bronx, New York 10467.

Adult $\mathrm{Pb}$ poisoning has been associated wtth depressed thyroid function (Arch. Intern. Med. 143:220, 1983). We have examined whether $\mathrm{Pb}$ poisoned children are also ar risk of $\mathrm{Pb}$-associated thyroid dysfunction. 16 children, 6 years of age or less, referred for evaluation of mildly elevated blood $\mathrm{Pb}(\mathrm{bPb})$ and exythrocyte protoporphyrin (BP) concentrations (bPb 30-47 $\mu \mathrm{g} / \mathrm{dl}$, EP 56-160 $\mathrm{\mu g} / \mathrm{d} 1$ ), underwent EDTA provocative testing (EPT). A11 had pre-EPT T/ measurements performed. 10 children qualiAli had pre-EPT T4 measurements performed. 10 children qualiPost-Rx $\mathrm{BPb}, \mathrm{EP}$ and $\mathrm{T}_{4}$ measurements were repeated in these children. T4 was measured by RIA; Pb by atomic absorption spectrophotometry and EP by fluorometry. Pearson product moment correlations were calculated:

$\begin{array}{llllll}\text { Results } & T_{4} \text { range } \quad \mathrm{n} \quad \mathrm{bPb} / \mathrm{T}_{4} & \mathrm{EP} / \mathrm{T}_{4} & \mathrm{uPb} / \mathrm{T}_{4} & \mathrm{uPb} / \mathrm{EDTA} / \mathrm{T} 4\end{array}$ $\begin{array}{lllllll}\text { Pre Rx: } & 9.0-14.7 \mu \mathrm{g} / \mathrm{d} 1 & 16 & .17 & -.23 & .15 & .30\end{array}$

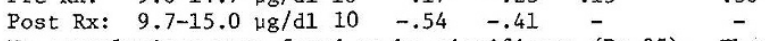
No correlations were found to be significant ( $P>.05)$. There was no difference in the mean $T_{4}$ concentration pre- and post-Rx $(\bar{x}=11.1$ and $11.6 \mu \mathrm{g} / \mathrm{dl}$, respectively $)$ in the 10 treated children. Conclusion: 1) We failed to find a significant effect of mild $\mathrm{Pb}$ poisoning $\left(\uparrow \mathrm{Pb},+\mathrm{EPT}\right.$ ) on serum $\mathrm{T}_{4}$ concentrations. 2) These data provide additional evidence to indicate that clinical and biochemical toxicity of $\mathrm{Pb}$ differs in children compared to adults.
464 TESTOSTERONE (T) BUT NOT OXANDROLONE (OX) INCREASES SPONTANEOUS (TO BUT HOT OXANDROLONE (OX) INCREASES (SmC) CONCENTRATIONS IN BOYS WITH CONSTITUTIONAL DELAY OF GROWTH AND ADOLESCENCE (CDGA). Kathleen M. Link, Robert M. Blizzard, Alan D. Rogol, Department of Pediatrics, University of Virginia Medical Center, Charlottesville, Virginia.

The effect of $\mathrm{T}$ and $\mathrm{OX}$ on $\mathrm{GH}$ and $\mathrm{SmC}$ concentrations was studled In boys with CDGA. Ten boys received $0 \times(0.1 \mathrm{mg} / \mathrm{kg} / \mathrm{d})$ for $65+5 \mathrm{~d}$ and 5 boys received T propionate ( $7.5 \mathrm{mg}$ IM $\times 7 \mathrm{~d}$ ) followed by T enanthate ( $100 \mathrm{mg}$ TM q mo for $3 \mathrm{mo}$ ). Serum GH was measured in samples obtained q 20 min for $24 \mathrm{hr}$ before and $65+5 \mathrm{~d}$ into ed In samples obtained q $20 \mathrm{~min}$ for $24 \mathrm{hr}$ before and $65 \pm 5 \mathrm{~d} 1 \mathrm{nto}$ period before and $65+5 \mathrm{~d}$ into therapy. The $24 \mathrm{hr}$ integrated concentration of $G H$ (ICG) was obtained from the mean of 72 samples and compared to that obtained from a pooled sample ( $p=N S)$. A pulse of $\mathrm{GH}$ was recorded if the peak level rose $>5 \mathrm{ng} / \mathrm{ml}$. We found no differences in the ICGH, in the number of GH secretory episodes, or in the SmC levels in boys treated with ox. However, in boys treated with $\mathrm{T}$ there were significant increases in the ICGH, the number of GH secretory ep1sodes and in the SMC levels.

\begin{tabular}{l|c|c|c|c|c|c|c|}
\hline $\mathrm{Rx}$ & $\mathrm{n}$ & ICGH (ng/m1) & \multicolumn{2}{c|}{$\mathrm{GH}$ Pulses } & \multicolumn{2}{c|}{ SmC (U/mI) } \\
\hline $\mathrm{OX}$ & & Pre Rx & Post & Pre Rx & Post & Pre Rx & Post \\
\hline $\mathrm{T}$ & 5 & 2.9 & 3.0 & 4 & 4.2 & 0.71 & 0.76 \\
\hline \multicolumn{2}{l}{} \\
\multicolumn{2}{l}{ We conclude that testerone therapy doubles the amount of $\mathrm{GH}$}
\end{tabular}

secreted dafly, although $0 X$ at $0.1 \mathrm{mg} / \mathrm{kg} / \mathrm{d}$ is without effect. This increase in $\mathrm{GH}$ secretion may contribute to the increased growth rate at puberty.

\section{CORTISOL LEVELS AND SKIN FOLD THICKNESS IN BPD}

465 Carol Luzzi, (Spon. by Leonard J. Graziani) Thomas Jefferson Univ. Hosp., Dept. Pediatrics, Phila. Some babies with BPD, a chronic disease causing significant metabolic stress, have been noted to take on a cushingoid appearance. We postulated that this appearance is a result
of stress induced elevated cortisol levels and altered body fat distribution (central/peripheral skin fold thickness). 29 infants were prospectively studied with 8 am serum cortisol levels between days 4 to 10 (wk 1) and during weeks 4 and 6 . Subscapular, periumbilical, and triceps skin fold measurements (SCF, PUF, and TF) were taken at wks 4 and 6 . Central to peripheral fold ratios (SCF/TF and PUF/TF) were calculated. At wk 6 , the patients were divided into 4 groups. $6 r 1,(\mathrm{~N}=7)$ "we11 infants", $\uparrow F_{1} 0_{2}<24 \mathrm{hrs}$; Gr 2 (N=2) "non-pulmonary illness", $\mathrm{PF}_{1} \mathrm{O}_{2}<24 \mathrm{hrs}+$ non-pulmonary illness $>48$ hrs duration; Gr $3(\mathrm{~N}=6)$, "acute pulmonary illness", ${ }^{\mathrm{N}} \mathrm{F}_{1} \mathrm{O}_{2}<2$ wks duration, \pm other il1ness; Gr $4(\mathrm{~N}=14) \mathrm{BPD},+\mathrm{F}_{1} \mathrm{O}_{2}>2$ wks duration plus xray signs of

\begin{tabular}{|c|c|c|c|c|c|c|c|}
\hline Group & Corti & $\left(M_{c}\right.$ & & $\mathrm{SCF} / \mathrm{T}$ & $(\mathrm{mm})$ & PUF/ & (mm) \\
\hline & WK 1 & WK 4 & WK 6 & WK 4 & WK 6 & WK 4 & WK 6 \\
\hline & $6.9+2.6$ & $7.4+7.4$ & $8.0 \pm 6.0$ & $1 \pm .13$ & $1.1 \pm .16$ & $99 \pm .15$ & $.94 \pm .12$ \\
\hline 3 & $\begin{array}{l}51.1+4 . \\
11 .+3\end{array}$ & $\begin{array}{l}8.4+9.8 \\
5.5+5.4\end{array}$ & 12062 & $\begin{array}{l}1.2 \pm \\
1.1+\end{array}$ & $1.0+$. & & \\
\hline 4 & & & & $1.1 \mp 0.2$ & & $92 \mp .22$ & \\
\hline
\end{tabular}
$\mathrm{BPD}+$ other illness. Data are presented as mean + S.D.

Group 2 does not have enough data for statistical analysis. Babies with BPD were compared to all non-BPD babies and groups 1 and 3 alone. Statistical analysis revealed no significant difference, $p<.05$, in cortisol levels or skin fold ratios.

\begin{abstract}
467 MARSHALL-SMITH SYNDROME: ANDROGEN ABNORMALITIES. 467 Lawrence J. Fenton) University of South Dakota School Medicine, Department of Pediatrics, sioux Falls.
In 1971 Marshall et al described a syndrome consisting of markedly accelerated skeletal maturation, relative failure to markedly accelerated skeletal maturation, relative failure to
thrive and dysmorphism. Since then 11 cases have been reported. thrive and dysmorphism. Since then 11 cases have been reported.
With the exception of an elevated testosterone in a neonatal female, hormonal evaluations have been normal. We present a male with Marshal1-Smith Syndrome with abnormal adrenal androgen production. A.S. was noted at birth to have a bone age of 2 yrs. At age 8 mos. the bone age was 6 yrs. Noted were generalized hirsutism, prominent forehead, low set ears, shallow orbits with prominent eyes, small triangular upturned nose, hypoplasia of facial bones, long, tapered fingers, inguinal testes, small scrotum and a penile length of $5 \frac{1}{4} \mathrm{~cm}$. The following were normal for age: $T_{4}$, a penile length of $5 \frac{1}{4} \mathrm{~cm}$. The following were normal for age: ' 4 ,
FSH, LH, somatomedin-C, testosterone, testicular response to $\mathrm{HCG}$, $\mathrm{FSH}$, $\mathrm{LH}$, somatomedin-C, testosterone, testicular response to HCG,
and androgen receptors in cultured skin fibroblasts. Seventeen and androgen receptors in cultured skin fibroblasts. Seventeen
hydroxyprogesterone (17-OHP) was elevated $(840 \mathrm{ng} / \mathrm{dl} ; \mathrm{nl} 30-100)$ as was androstenedione $(67 \mathrm{ng} / \mathrm{dl} ; \mathrm{nk}<50)$. An ACTH stimulation test was done. A $30 \mathrm{~min}$. increase in $17-0 \mathrm{HP}$ of $23.4 \mathrm{ng} / \mathrm{dl} / \mathrm{min}$. suggested an adrena? enzymatic defect and hydrocortisone 20 $\mathrm{mg} / \mathrm{m}^{2} /$ day was begun. The androstenedione decreased to $13 / \mathrm{ng} / \mathrm{dl}$ and on therapy has remained norma 7 . ACTH stimulation tests were performed on both parents. The 30 min. increase in 17-0HP was performed on both parents. The 30 min. increase in $17-0 \mathrm{HP}$ was $n<6.5 \mathrm{ng} / \mathrm{dl} / \mathrm{min}$ ) suggesting a heterozygous state for congenital
adrenal hyperplasia. It is speculated that an inherited abnormat ity in androgen production may be contributory to the osseous ity in androgen production may be contributory
maturation seen in the Marsha17-Smith Syndrome.
\end{abstract}

AMINO ACID RESIDUES 93-96 OF THE HUMAN GROWTH HORMON MOLECULE ARE IMPORTANT FOR POLYCLONAL ANTISERUM RECO Ke11y, Christopher Y. Wendy J. Maury, Alan D. Rogol, Thaddeus E. and Interna1 Medicine, University of Virginia School of Medicine, and Internal Medicine, Unive

Charlottesville, Virginfa.
The precise regions of the human growth hormone (hGH) molecule that mediate its biologic effects and 1mmunoreactivity are not known. To address this issue, we have introduced mutations into the coding region of a cloned hGH gene and expressed the resulting mutants in a eukaryotic expression vector. Two clones with alterations in the DNA sequences encoding amino actds 93-96 within the hGH molecule were created by the insertion of Bam HI DNA linkers into the Mst II site. The hGH derived from these mutants had characteristics indistinguishable from those of wild type hGr in the NB-2 cell lactogenic assay, the TM-9 cell radioreceptor assay, and in the binding of four anti-hGH monoclonal antibodies. However, significant differences were observed between the mutants and standard human pituitary $\mathrm{GH}$ or hGH produced by the normal gene in the binding of polyclonal hGH antisera. Both mutants bound to the polyclonal antibody poorly but did not displace labeled standard hormone in a proportionate manner.

These results suggest that amino acids $93-96$ of $\mathrm{hGH}$ regulate the expression of antigenic determinants that are detected by polyclonal antiserum, but these determinants are distinct from those recognized by the four monoclonal antibodies that were tested. Moreover, hGH molecules with abnormal 1 mmunologic re-
activity may retain normal biologic activities in certain assays. 